\title{
THE ANALYSIS OF LOW NOISE PROTECTION BARRIERS INFLUENCE ON TRAM TRAFFIC NOISE LEVELS
}

\author{
Maja Ahac, Sc.novice, MCE, University of Zagreb, Faculty of Civil Engineering, \\ Department for Transportation, e-mail: mahac@ grad.hr
}

Stjepan Lakušić, Prof., PhdCE, University of Zagreb, Faculty of Civil Engineering, Department for Transportation, e-mail: laki@grad.hr

Saša Ahac, Sc.novice, MCE, University of Zagreb, Faculty of Civil Engineering, Department for Transportation, e-mail: sahac@grad.hr

Vesna Dragčević, Prof., PhdCE, University of Zagreb, Faculty of Civil Engineering, Department for Transportation, e-mail: vesnad@grad.hr

\begin{abstract}
The paper describes the analysis of tram traffic noise situation in residential areas in the vicinity of Drzic Avenue, one of the major routes between the northern and southern part of the Croatian capital city Zagreb, and the effect of low barriers placed by the tracks on tram noise mitigation. In order to evaluate the effect of planned protection measure, noise models were produced and verified with short-term field measurements. Calculations were conducted by means of noise prediction software, using European interim noise prediction method and 3D model of analyzed area. Finally, the results of noise calculations for existing tram traffic situation and planned measure of protection are presented on noise maps.
\end{abstract}

Keywords: tram traffic, urban noise modeling, low noise protection barriers

\section{INTRODUCTION}

Environmental noise, traffic noise especially, presents a serious problem in densely populated urban areas, where residential and buisiness centers are situated in the proximity of main traffic corridors. This results in a pronounced negative impact of traffic noise on urban residents: it deteriorates human health, causing fatigue and reduced work capacity and also interferes with communication, concentration, relaxation and sleep. In Zagreb, problem of traffic noise control is particularly pronounced in downtown areas, where many residents occupy high-rise buildings placed next to tram routes. Since the tram traffic is the backbone of the public municipal transport in Zagreb, with the tram passage frequency of few minutes, the question arises what could be done to efficiently reduce the tram traffic noise. 
Increasing the distance between the track and the receiver is one of the most effective measures of noise and vibration reduction. At a distance of $500 \mathrm{~m}$ from the rail track people no longer perceive the rail traffic vibrations [1], while the air borne noise decreases by about $20 \mathrm{~dB}$ (A) [2]. Unfortunately, this measure can only be applied on planned new routes, and even then it is only appropriate if the cost of land purchase is less than the estimated cost of the implementation of other mitigation measures. Therefore, this is not an appropriate measure to be applied in the current state of Zagreb's urban development.

Foreign experience has shown that various measures can be implemented to control and reduce tram traffic noise at its source (application of the "quiet" vehicles, driving speed limitation, regular maintenance of driving surface, traffic management, etc.). Implementation of noise protection barriers is the most effective measure of noise reduction. Barriers enable the reduction of noise at the observed point of immission in the range from 5 to $15 \mathrm{~dB}(\mathrm{~A})$, depending on the height and length of the barrier, material from which it is constructed and the distance between the source and the receiver [3].

This paper describes modelling and analysis of tram traffic noise situation in residential areas in the vicinity of Drzic Avenue, and the effect of low height concrete barriers placed by the tracks on tram noise mitigation.

\section{TRAM NOISE CALCULATION MODEL}

Drzic Avenue is one of the major traffic routes between the northern and southern parts of the town (Figure 1). It consists of two carriageways, one for each driving direction, with three lanes on every carriageway. The tram tracks are situated in the middle corridor between the two carriageways (Figure 2). At the tram stations, pedestrian access is enabled by underpasses.

At the observed $1.2 \mathrm{~km}$ long section, the street is surrounded by densely populated residential areas [4], in which maximum allowed equivalent traffic noise levels are $55 \mathrm{~dB}(\mathrm{~A})$ for the period "day" and "evening", i.e. from 07:00 til 23:00 hours, and $45 \mathrm{~dB}(\mathrm{~A})$ for the night period, i.e. from 23:00 till 07:00 hours [5]. 


\section{ROMANIAN JOURNAL OF TRANSPORT INFRASTRUCTURE}

Maja Ahac, Stjepan Lakušić, Saša Ahac, Vesna Dragčević,

The analysis of low noise protection barriers influence on tram traffic noise levels

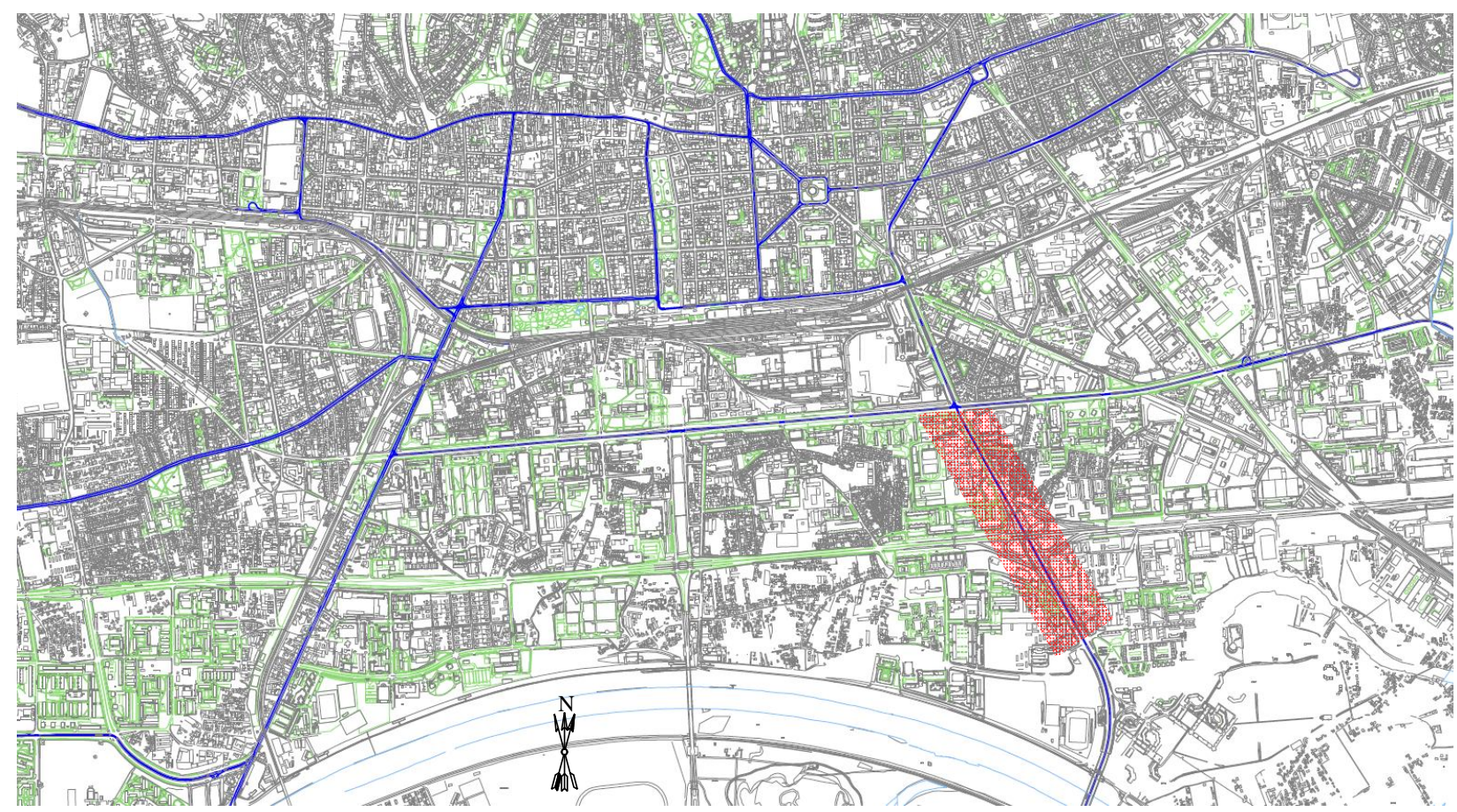

Figure 1. Drzic Avenue wider area

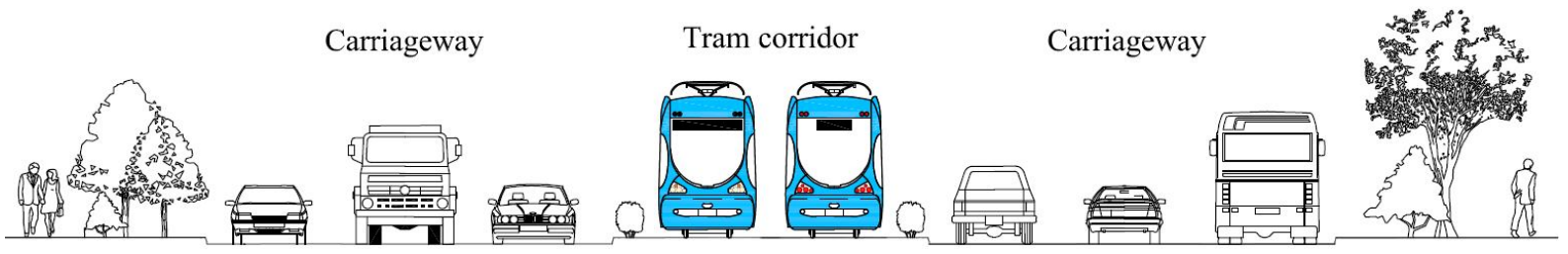

Figure 2. Drzic Avenue cross section

\subsection{Input data for noise calculation model}

The calculation was conducted by means of noise calculation package Lima and Dutch RMR 1997 method for calculation of rail traffic noise as European interim calculation method defined by Regulations [6]. Table 1 shows the input data used in noise modelling, requested by the applied interim noise calculation method and software package. 
Table 1. Input data used for creation of noise calculation model of tram traffic in Drzic Avenue

\begin{tabular}{|l|l|}
\hline Noise emission model & Noise propagation model \\
\hline Railway superstructure type & Terrain brakelines and elevation points \\
\hline Vehicle type (category) & Ground surface type \\
\hline Traffic load & Barrier locations and heights \\
\hline Average speed & Building locations and heights \\
\hline Percentage of braking vehicles & Atmospheric attenuation \\
\hline Source location & Meteorological correction \\
\hline
\end{tabular}

Tram tracks on observed railway section consist of grooved rails Ri-60, covered with crushed stone, that are merged with continuous concrete base plate by direct elastic fastening system (Figure 3 ).

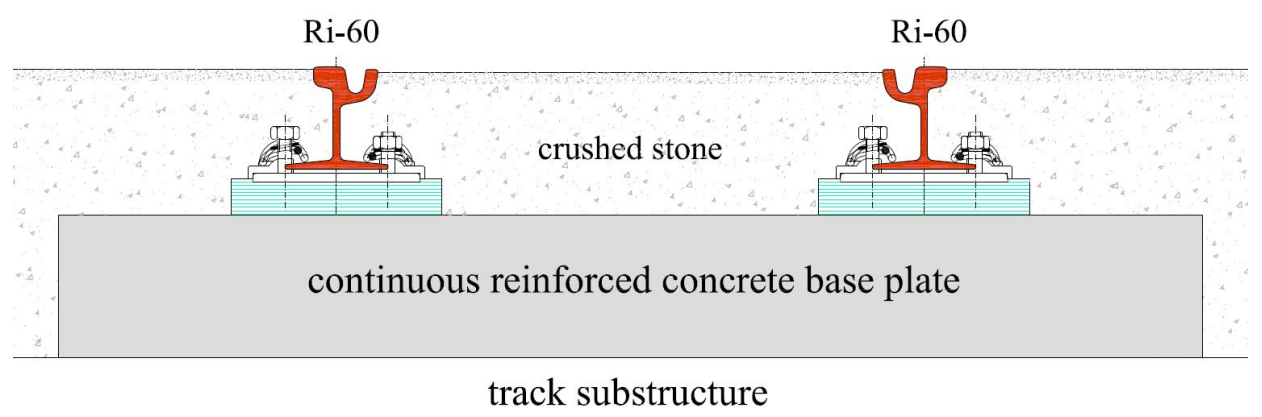

Figure 3. Tram track superstructure in Drzic Avenue

As for the traffic load, there are four tram lines that operate on tracks in Drzic Avenue, with average tram passing frequency of 3 minutes, i.e. 370 trams pass through this part of the Zagreb's tram network daily. Hourly tram number needed as an input for noise calculation was derived from Zagreb Municipality Transit System - ZET Ltd. tram timetables [7].

The maximum allowed tram speed on Drzic Avenue is $30 \mathrm{~km} / \mathrm{h}$. Since there are two tram stations and a major road intersection in the observed section of tram corridor, tracks were divided into subsections on which trams run at a constant average speed of $20 \mathrm{~km} / \mathrm{h}$, accelerate, and decelerte (Figure 4). 
ROMANIAN JOURNAL

\section{OF TRANSPORT INFRASTRUCTURE}

Maja Ahac, Stjepan Lakušić, Saša Ahac, Vesna Dragčević,

The analysis of low noise protection barriers influence on tram traffic noise levels

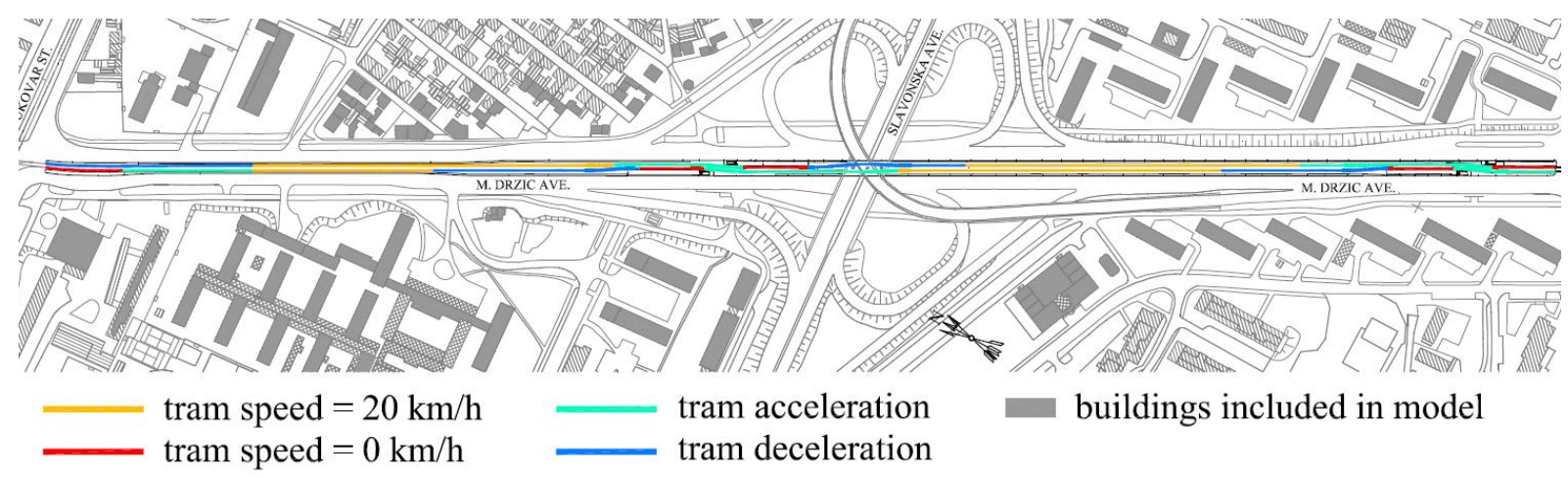

Figure 4. Tram track subsections

Data on the remaining noise emission and propagation parameters was collected during the reconnaissance of the area and then consolidated in digital 3D terrain model constructed by examining the available digital maps of the area (orthophoto, HOK - Croatian Basic Map, GUP - Master Plan) [8].

The sound absorption coefficients and occurrence of favourable sound propagation conditions have been introduced in the calculation using the values given by the calculation method, while data on relative humidity and air temperature during field measurements was taken from the Meteorological and Hydrologycal Service (MHSC) [9].

\subsection{Model validation}

The reliability of the noise calculation model must be confirmed by comparing the results of calculations and results of on-field noise levels measurements.

For the purpose of the model validation, the results of short-time 15minute measurements of the tram traffic noise levels in Drzic Avenue were used. Measurements were carried out by Brüel \& Kjær sound level meter positioned at the distance of 1 meter from the tram track, and at the height of 1.2 $\mathrm{m}$ above the running surface of the rail, under favourable meteorological conditions. Two measurements were performed during the period "day", and one at period "night" [10].

According to the recommendation of the noise calculation and abatement profession experts, if the difference between the results of the calculation model and measurements is less than $3 \mathrm{~dB}(\mathrm{~A})$, precision of the calculation model is considered satisfactory [8]. Measurement and modelling results of the noise levels caused by the tram traffic are presented in the Table 2. Comparison 
between calculated and measured equivalent noise levels at Drzic Avenue, showed that the differences were within permissible limits.

Table 2. Noise measuring and modelling results

\begin{tabular}{|l|l|l|}
\hline \multirow{2}{*}{ Time period } & Measured values & Modelled values \\
\cline { 2 - 3 } & $\mathbf{L}_{\mathrm{eq}}[\mathbf{d B}(\mathbf{A})]$ & $\mathbf{L}_{\mathrm{eq}}[\mathbf{d B}(\mathbf{A})]$ \\
\hline \multirow{2}{*}{ Day } & 78.3 & 76.5 \\
\cline { 2 - 3 } & 76.7 & 70.8 \\
\hline Night & 73.3 & \\
\hline
\end{tabular}

\section{EFFECT OF LOW HEIGHT CONCRETE B ARRIERS}

Model validation confirmed the reliability of its application for the prediction of tram traffic noise levels. Noise calculation was repeated with the same input parameters, but this time the model contained additional feature concrete, high-absorbent, 1.2 meters high sound barrier placed between carriage ways and tram tracks in the whole length of the analyzed corridor.

Barrier height is defined based on the height of the lower edge of the lowfloor tram window, so it wouldn't obstruct the tram passengers view. On open track sections, barrier was placed 1.5 meters from each track axis, as shown in Figure 5. At the station platforms, the barrier was placed in the position of the existing fence, as shown in Figure 6.

The placement, height, material and overall construction type of the low height concrete barrier (assembly or semi-assembly) is suitable because of the following advantages:

- possibility of fast construction by light machinery, so traffic on Drzic Avenue would be disturbed as little as possible,

- sufficient mechanical stability and resistance of the structure,

- good protection from tram traffic noise,

- minimum expenses of barrier construction and maintenance during exploitation, and

- easy barrier disassembly in case of tram track maintenance or reconstruction.

Additionaly, by replacing the existing hedge, the barrier would serve as a rigid protective fence between the tram tracks and other street users, and would improve the overall traffic safety in this area.

The results of noise calculations for existing tram traffic situation, and planned measure of noise protection are presented on noise maps (Fig.7 and 8). 


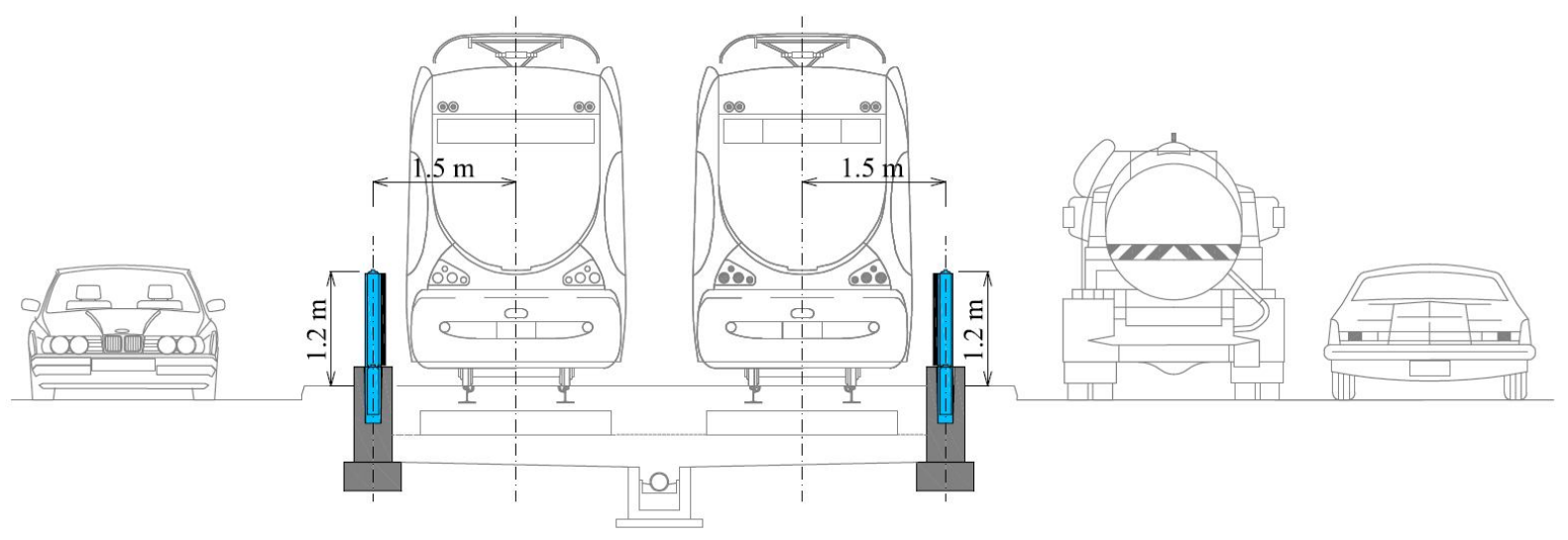

Figure 5. Barrier construction and placement on open track

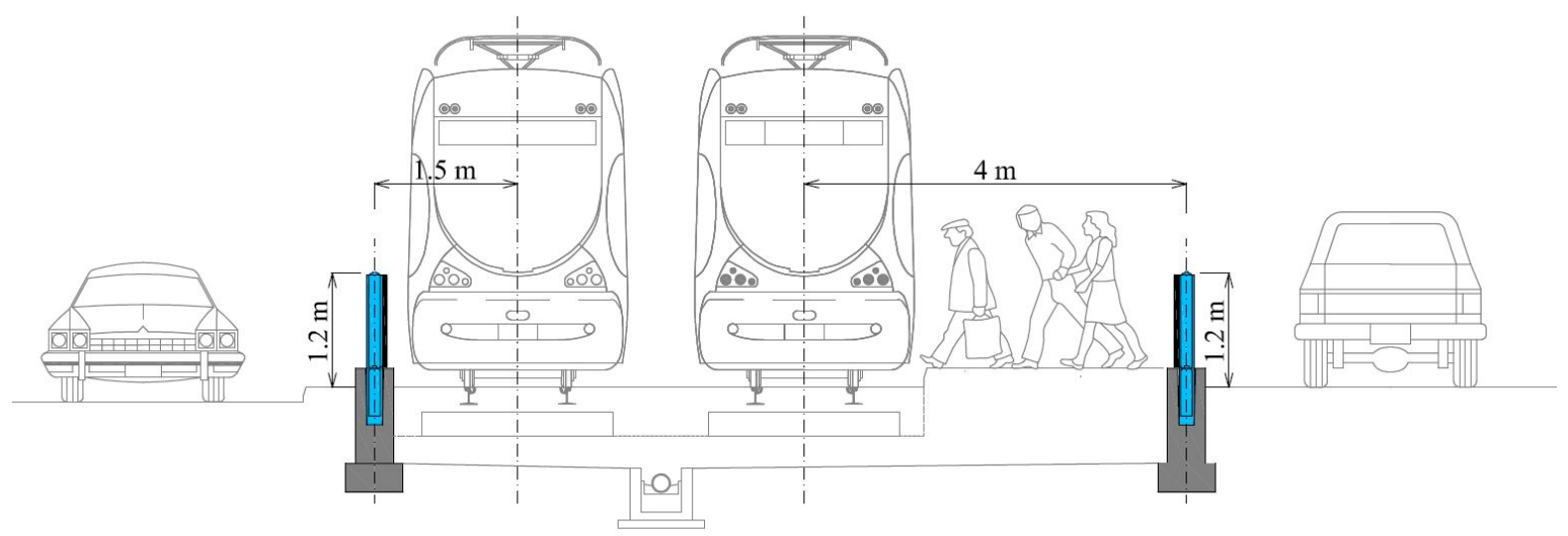

Figure 6. Barrier construction and placement at the tram station

It can be seen from the noise maps that the barrier instalation could result in average noise reduction of $10 \mathrm{~dB}(\mathrm{~A})$. Predicted noise levels for the situation with noise protection barrier fully meet the permissible noise levels in the analysed area during the period "day". For the period "night" noise is also reduced, but the noise level still does not fully comply to the permitted limits. 


\section{ROMANIAN JOURNAL OF TRANSPORT INFRASTRUCTURE}

Maja Ahac, Stjepan Lakušić, Saša Ahac, Vesna Dragčević,

The analysis of low noise protection barriers influence on tram traffic noise levels
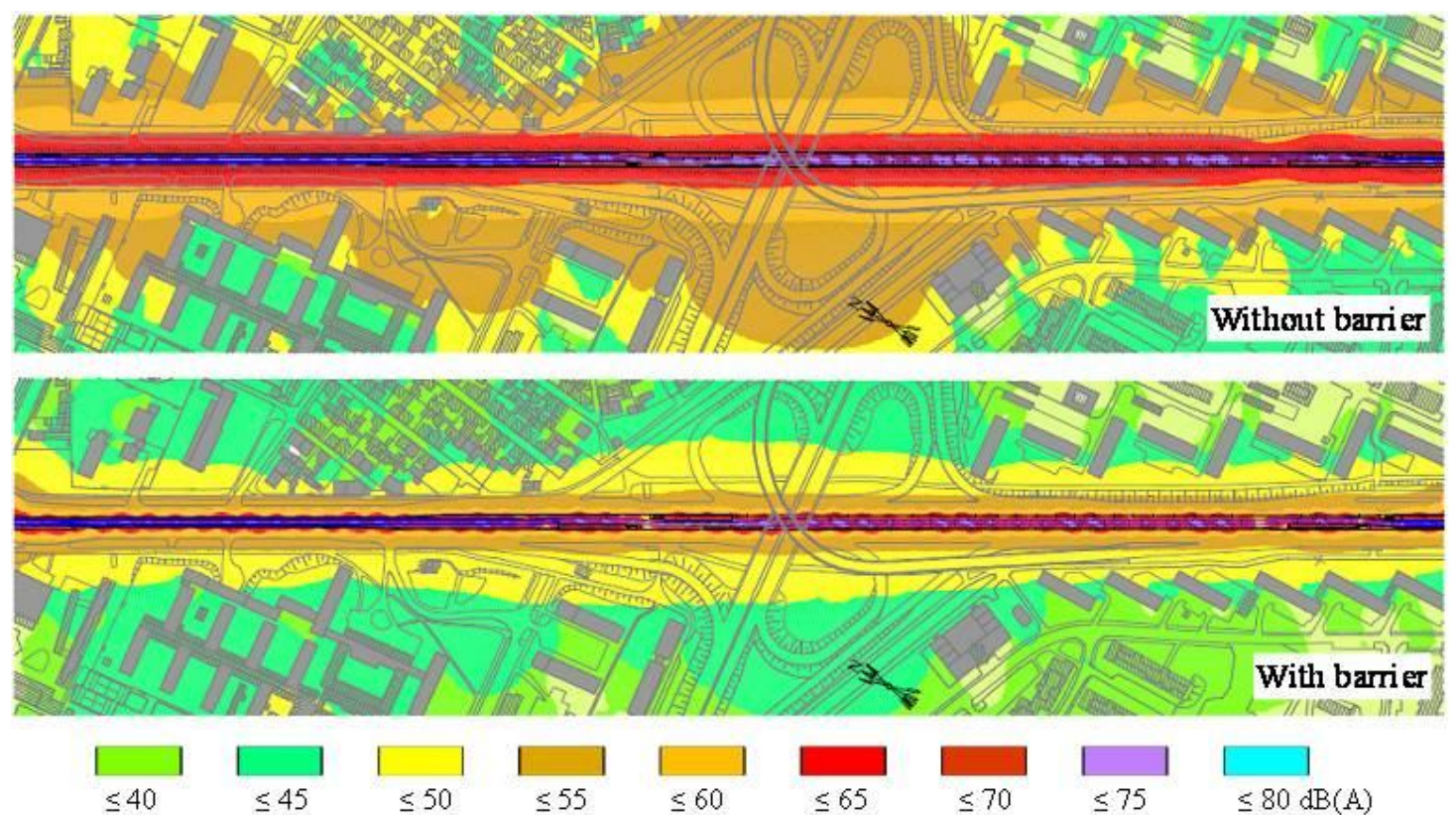

Figure 7. Noise maps for day period at $1.2 \mathrm{~m}$
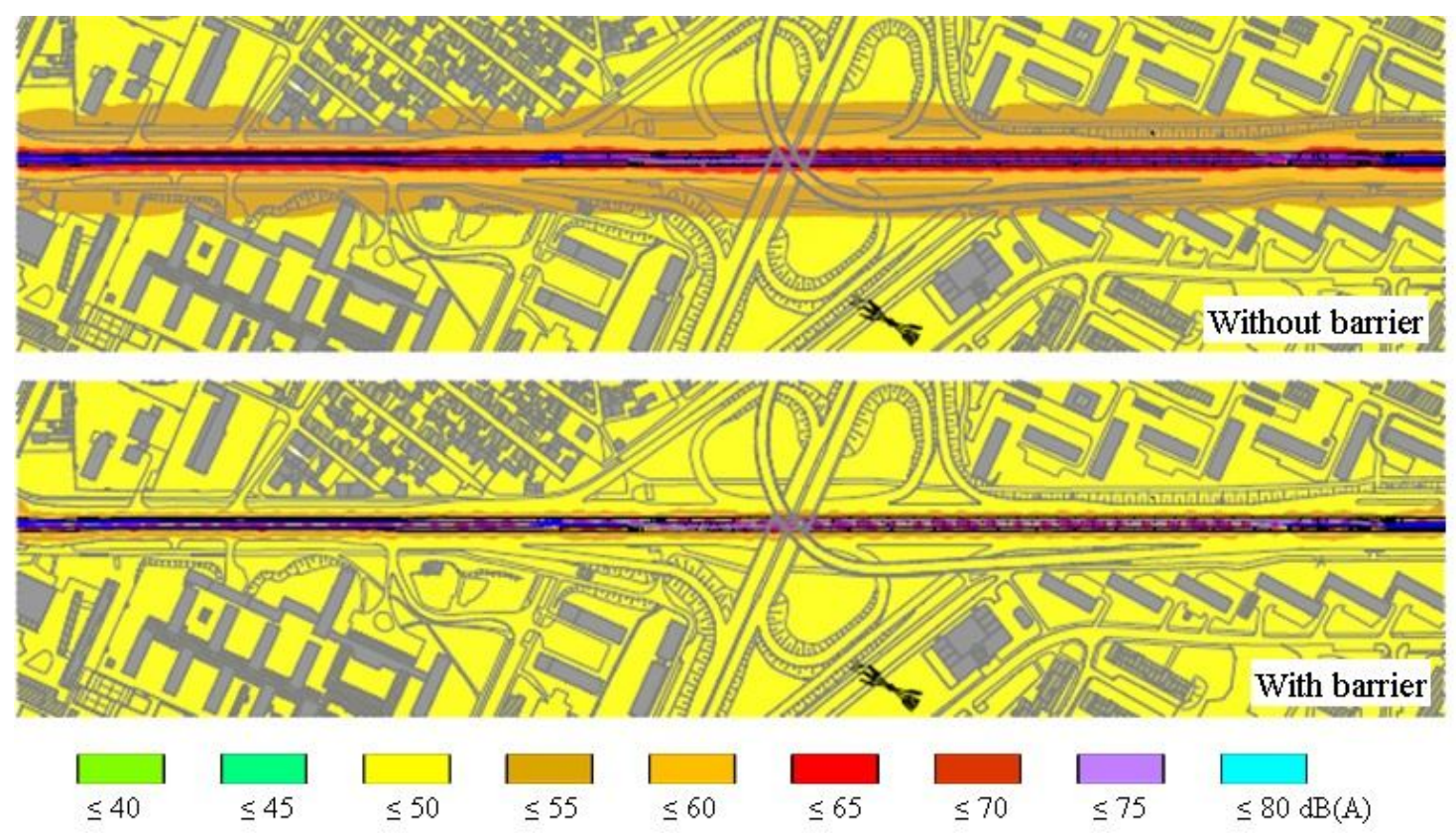

Figure 8. Noise maps for night period at $1.2 \mathrm{~m}$

\section{CONCLUSIONS}

On Zagreb's tram tracks, due to spatial, feasible and financial limitations, noise mitigation measures such as track superstructure upgrade or construction of high noise barriers are not favorable options. Because of that, from the 
ROMANIAN JOURNAL

\section{OF TRANSPORT INFRASTRUCTURE}

Maja Ahac, Stjepan Lakušić, Saša Ahac, Vesna Dragčević,

The analysis of low noise protection barriers influence on tram traffic noise levels

viewpoint of efficiency and cost-effectiveness, construction of low height noise protection barriers placed next to the tracks arose as the optimum measure for reduction of tram traffic noise levels.

The efficiency of proposed noise mitigation measure was evaluated by the means of validated tram noise propagation model and described using noise maps. The investigation showed that construction of $1.2 \mathrm{~m}$ high, high-absorbent barrier at the distance of 1.5 meters from tram track could reduce noise by 10 $\mathrm{dB}(\mathrm{A})$. This result, combined with other advantages of proposed measure that include it's simple construction, posibility of installation under undisturbed traffic conditions and increase in traffic safety by separation of tram, road, and pedestrian traffic, makes described low height barriers cost effective urban traffic environment improvement measure.

\section{REFERENCES}

[1]. “Assessing vibration: a technical guideline”, Environmental Noise Management, Department of Environment and Conservation NSW, 2006.

[2]. S. LAKUŠIĆ, M. AHAC: "Rail traffic noise and vibration mitigation measures in urban areas”, Technical Gazette 19, 2(2012), 427-435.

[3]. "Transit noise and vibration impact assessment”, U.S. Department of Transportation, Federal Transit Administration (FTA), Office of Planning and Environment, 2006.

[4]. “Master Plan of City of Zagreb”, Official Herald, 14/2003.

[5]. "Highest permitted noise level regulation for places where people work and reside", Official Journal, NN 145/2004.

[6]. "Regulation on the noise mapping and content of noise maps and action plans and the calculation of permitted noise indicators", Official Journal, NN 75/2009.

[7]. Zagreb Municipality Transit System Ltd. web page: http://www.zet.hr/

[8]. V. DRAGČEVIĆ, S. LAKUŠIĆ, S. AHAC: "The applicability of 3D model in calculation of road traffic noise level”, Proceedings of the - $1^{\text {st }}$ International Conference on Road and Rail Infrastructure "CETRA 2010", organized by the University of Zagreb, Faculty of Civil Enginering, Opatija 17-18 May 2010.

[9]. Meteorological and Hydrologycal Service web page: http://meteo.hr/index.php

[10]. S. LAKUŠIĆ, V. DRAGČEVIĆ, T. RUKAVINA: "The impact of tram track fastening systems on noise level”, URBAN TRANSPORT XI / Brebbia, C.A.; Wadhwa, L.C. (ed.). - Southampton, Boston: WIT Press , 2005, 487-497. 